\title{
Perspectives on Breathing in Sports and Health
}

\section{Lorraine R. Brilla*}

PEHR Department, Western Washington University, Bellingham, USA

\section{Introduction}

Breathing is taken for granted, seldom a conscious effort until one is "out of breath." Breath can be held, tight, rapid and shallow, or deep and slow. There are anecdotal examples of activities that breathing interventions can support sports performance and have functional implications. Some competitors sleep with a weight on their chest to strengthen breathing muscles and increase their capacity to force air in to the lungs. For breathing enhancement, some individuals use straw breathing to restrict airflow to stimulate the impulse to inhale. Research has been done on pulmonary function and physical performance, where it may be presumed that participants have highly functional responses. Remarkably, it was noted in 1986 that a healthy pulmonary system may be a limiting factor; affecting oxygen levels plus $\mathrm{CO}_{2}$ transport and elimination during high level physical exertion in well trained athletes [1]. A number of untested speculations were identified with the admonition that a bit more data would be useful.

Although there has been some research to identify pulmonary limitations in physical performance, the research has focused especially on certain cardiopulmonary ceilings or interventions attempting to enhance respiratory muscle function. The three identified areas of pulmonary limitations in physical activity are: flow limitation which includes exercise induced asthma (EIA), exercise induced arterial hypoxemia (EIAH), and fatigue of the respiratory muscles [2-5]. Interventions for enhancing pulmonary function during exercise have centered to a great degree on respiratory muscle training [5-11], and more recently on high intensity training $[12,13]$.

Additionally, health related benefits for breathing interventions have been reported for various diseases [14-21], ubiquitously chronic obstructive pulmonary disease (COPD) [22-24]. Breathing training has been used as an adjunct therapy for some pain conditions [2529], including childbirth labor [30,31]. The mechanisms may be direct, as an increase in pulmonary function, or elicited processes, such as neuroendocrine adjustments associated with the respiratory improvements, for efficacy in specific health disorders. Commonly available literature reviews emphasized that there is a paucity of studies which leads to insufficient evidence about intervention strategies and putative outcomes.

This commentary details some effects related to breathing facets in physical performance and health-related applications. A summary with inferences is presented and where the current evidence might lead forthcoming research.

\section{Breathing: Physical Performance}

Physical performance is limited primarily by the muscular, cardiovascular, and respiratory systems. In healthy individuals, the systems limiting performance follow a hierarchical order from sedentary subjects being restricted by muscle function; then, generally fit individuals having cardiovascular constraints on physical efforts, with elite athletes many times reaching the ceiling effect because of pulmonary restrictions. Environmental factors may also contribute to exercise limitations, especially altitude [32,33]. However, generally reported effects of pulmonary limitations on effort are observed in healthy, high level competitors in standard environmental conditions [1-5].
Noting that the pulmonary system may be a limiting factor to high level physical performance, attention has been directed to respiratory muscle training, with emphasis on inspiratory muscle training. Sports that have competitors with large lung volumes such as cycling and rowing have been the prime attention of interventions. Inspiratory muscle training (IMT) improves cycling time-trial performance [34]. The study researchers attributed the improvement to anaerobic work capacity but not critical power. The determination of anaerobic work capacity does include an aerobic component which may have responded to the IMT. Evidence also shows that performance enhancements observed in cyclists after IMT are accompanied by a decrease in inspiratory muscle fatigue [10]. Other researchers have credited the apparent increase in respiratory function in athletes to a difference in the breathing pattern adopted rather than respiratory muscle strength or efficiency differences from intervention [35].

More recent research efforts have shown that IMT can reduce the magnitude of the $\mathrm{VO}_{2}$ slow component, associated with an enhanced exercise tolerance $[6,7]$. The mechanisms that may elicit the outcome were postulated as reduced muscle fatigue either by improving muscle oxidative capacity or by enhancing muscle $\mathrm{O}_{2}$ delivery or local matching of blood and tissue oxygen [6]. Four weeks of IMT at a load of 30 breaths twice daily at $50 \%$ of maximum inspiratory pressure (MIP) reduced inspiratory muscle fatigue and diminished the $\mathrm{VO}_{2}$ slow-component amplitude in maximal cycling exercise. These factors resulted in an improved exercise tolerance. It was acknowledged that fatigue of the respiratory muscles during intense exercise might compromise leg blood flow, and this area requires further study. Future intervention enhancement to maximize IMT impact on the $\mathrm{VO}_{2}$ slow component might prove valuable in sports performance and possibly greater exercise tolerance in elderly or patient populations.

Although various IMT workloads have been effective for measured outcomes, higher intensity workloads tend to show better results. Studies have shown that workloads at $80 \%$ MIP results increases in lung volumes, work capacity, power output, and decreases in exercising heart rate and perceived exertion $[9,5]$. Inspiratory muscle training intensities which are lower than $40 \%$ of maximal workload generally do not translate into quantitative functional outcomes in healthy subjects.

\section{Breathing: Health Related Applications}

Breathing interventions have been applied in health care settings. The body of research on breathing effects, however, is in its nascence and interventions vary. IMT is used [15-24], as in sports performance studies, as well as other methodologies. Measured outcomes are in areas from clinical assessments such as pain [25-31] to more objective

*Corresponding author: Lorraine R. Brilla, PEHR Department, Western Washington University, Bellingham, WA 98225-9067; E-mail: Lorrie.Brilla@wwu.edu

Received August 18, 2012; Accepted August 18, 2012; Published August 21 2012

Citation: Brilla LR (2012) Perspectives on Breathing in Sports and Health. J Sports Med Doping Stud 2:e121. doi:10.4172/2161-0673.1000e121

Copyright: (c) 2012 Brilla LR. This is an open-access article distributed under the terms of the Creative Commons Attribution License, which permits unrestricted use, distribution, and reproduction in any medium, provided the original author and source are credited. 
processes, with examples being autonomic nervous system influences and blood pressure responses [15,17,35-37].

There is a long history of pranayama breathing, without extensive supporting research literature on positive effects. Pranayamic breathing is associated with decreased oxygen consumption, heart rate, and blood pressure, with increased EEG theta wave amplitude and parasympathetic activity [38]. It is proposed that such voluntary slow deep breathing functionally resets the autonomic nervous system through stretchinduced inhibitory signals and hyperpolarization currents. Stretching of lung tissue produces inhibitory signals of slowly adapting stretch receptors and fibroblastic hyperpolarization currents. Immediate effects were reported after five minutes of pranayama exercise [39]. Diastolic pressure and mean pressure were significantly reduced. Researchers intimated that changes were elicited by parasympathetic influence on cardiovascular system.

More recently, abdominal-breathing or diaphragmatic-breathing methods have increased in acceptance. The efficacy of slow, abdominal breathing has been demonstrated in reducing blood pressure (BP) in hypertensive [35] and pre-hypertensive patients [36]. Slow breathing for three months decreased BP response in hand grip and cold pressure tests [35]. Longitudinally, slow abdominal breathing lowered systolic blood pressure $8.4 \mathrm{mmHg}$ and diastolic blood pressure $3.9 \mathrm{mmHg}$ in subjects with pre-hypertension, both significant effects [36]. Also, the electrocardiographic R-R interval increased significantly. Both studies showed that $\mathrm{BP}$ improvements may be related to autonomic nervous system effects, with reduced sympathetic activity and enhanced vagal influence. In other patient populations such as those with diabetes, the blunted baroreflex sensitivity typical in patients with diabetes was restored to the level of control subjects with slow breathing intervention [40]. These studies demonstrate that slow breathing may be efficacious treatment to assist in $\mathrm{BP}$ control, with putative mechanisms related to autonomic function.

Slow, deep breathing is also an ancillary application to ameliorate pain. When heat pain was induced, thermal pain threshold and pain tolerance were significantly higher during slow deep breathing, with increased amplitude of vagal cardiac markers [26]. The researchers proposed that possible cardiorespiratory processes are responsible for mediating breathing-induced analgesia. Measuring mean skin conductance levels which represent a proxy for sympathetic activity, deep and slow breathing significantly decreased sympathetic arousal and pain perception [25]. This report also supports breathing for analgesia. Breathing is effective in reducing the pain and distress associated with childhood immunizations [27] and labor during childbirth, especially in latent labor before delivery [31].

Other conditions, asthma [15], stroke [16], cystic fibrosis [17], have limited research support but there are indications that breathing may be a beneficial adjunct therapy. COPD has the most substantial support for breathing interventions [22-24]. When IMT is used, workloads are in the range of $30 \%$ to $80 \%$ MIP, depending on the patient population. The literature is fairly extensive on COPD and oxidative stress. Strategies to decrease oxidant burden in COPD has identified various antioxidant modulators and anti-inflammatory adjuncts [41]. Exercised breathing can attenuate increases in inflammatory markers such as IL-6 and TBARS, effectively influencing the cytokine response [42].

Across the literature, there are examples of breathing intervention efficacy in treatment of assorted health complications. The mechanisms by which breathing therapy ameliorates respiratory difficulties, improves disease conditions, and related pain have not been fully identified, but there appears to be a strong case for neuroendocrine adjustments.

\section{Data and Deductions}

The literature reports show that breathing, whether it is part of the exercise response or as directed exercise training modality, not only influences the pulmonary system, but has sundry effects on other functions, in particular, neuroendocrine responses. Specifically, enhanced breathing function is associated with improved sympathovagal tone, antioxidant effects, and putative, augmented antiinflammatory utility.

Breathing is generally regarded as an unconscious function and so basic to sustaining life that respiratory enhancements have not been adequately explored to the extent of identifying not only the pulmonary effects but uncovering other systemic influences, as well. Conceivably, more consciousness about breathing and function is warranted. Thich Nhat Hahn, a Buddhist monk and author, writes "Breathing in, I know I am breathing in; breathing out, I know that I am breathing out" denoting that breathing may be better appreciated if noticed and studied in more detail.

Future research should be directed towards the development of training effects that notably affect sports performance and the course of diseases. Although there is support for neuroendocrine effects, antioxidant enhancements, and anti-inflammatory augmentation, the mechanisms that contribute to the effects should be more clearly elucidated. Is a health benefit of exercise that it induces deep breathing? As expressed by Dempsey, a bit more data would be useful [1].

\section{References}

1. Dempsey JA (1986) J.B. Wolffe memorial lecture. Is the lung built for exercise? Med Sci Sports Exerc 18: 143-155.

2. McKenzie DC (2012) Respiratory physiology: adaptations to high-leve exercise. Br J Sports Med 46: 381-384.

3. Guenette JA, Romer LM, Querido JS, Chua R, Eves ND, et al. (2010) Sex differences in exercise-induced diaphragmatic fatigue in endurance-trained athletes. J Appl Physiol 109: 35-46.

4. Dempsey JA, McKenzie DC, Haverkamp HC, Eldridge MW (2008) Update in the understanding of respiratory limitations to exercise performance in fit, active adults. Chest 134: 613-622.

5. Enright SJ, Unnithan VB (2011) Effect of inspiratory muscle training intensities on pulmonary function and work capacity in people who are healthy: a randomized controlled trial. Phys Ther 91: 894-905.

6. Jones AM, Grassi B, Christensen PM, Krustrup P, Bangsbo J, et al. (2011) Slow component of VO2 kinetics: mechanistic bases and practical applications. Med Sci Sports Exerc 43: 2046-2062.

7. Bailey SJ, Romer LM, Kelly J, Wilkerson DP, DiMenna FJ, et al. (2010) Inspiratory muscle training enhances pulmonary $\mathrm{O}_{2}$ uptake kinetics and highintensity exercise tolerance in humans. J Appl Physiol 109: 457-468.

8. Romer LM, Polkey MI (2008) Exercise-induced respiratory muscle fatigue: implications for performance. J Appl Physiol 104: 879-888.

9. Gething AD, Passfield L, Davies B (2004) The effects of different inspiratory muscle training intensities on exercising heart rate and perceived exertion. Eur J Appl Physiol 92: 50-55.

10. Romer LM, McConnell AK, Jones DA (2002) Inspiratory muscle fatigue in trained cyclists: effects of inspiratory muscle training. Med Sci Sports Exerc 34: 785-792

11. Eastwood PR, Hillman DR, Finucane KE (2001) Inspiratory muscle performance in endurance athletes and sedentary subjects. Respirology 6: 95-104.

12. Dunham C, Harms CA (2012) Effects of high-intensity interval training on pulmonary function. Eur J Appl Physiol 112: 3061-3068.

13. Laursen PB, Jenkins DG (2002) The scientific basis for high-intensity interval training: optimising training programmes and maximising performance in highly trained endurance athletes. Sports Med 32: 53-73. 
14. Bausewein C, Booth S, Gysels M, Higginson I (2008) Non-pharmacological interventions for breathlessness in advanced stages of malignant and nonmalignant diseases. Cochrane Database Syst Rev 16: CD005623.

15. Ferreira JB, Plentz RD, Stein C, Casali KR, Arena R, et al. (2011) Inspiratory muscle training reduces blood pressure and sympathetic activity in hypertensive patients: A randomized controlled trial. Int J Cardiol.

16. Laoutaris ID, Adamopoulos S, Manginas A, Panagiotakos DB, Kallistratos MS, et al. (2012) Benefits of combined aerobic/resistance/inspiratory training in patients with chronic heart failure. A complete exercise model? A prospective randomised study. Int J Cardiol.

17. Laoutaris ID, Dritsas A, Brown MD, Manginas A, Kallistratos MS, et al. (2008) Effects of inspiratory muscle training on autonomic activity, endothelial vasodilator function, and $\mathrm{N}$-terminal pro-brain natriuretic peptide levels in chronic heart failure. J Cardiopulm Rehabil Prev 28: 99-106.

18. Pollock RD, Rafferty GF, Moxham J, Kalra L (2012) Respiratory muscle strength and training in stroke and neurology: a systematic review. Int J Stroke.

19. Ram FS, Wellington SR, Barnes NC (2003) Inspiratory muscle training for asthma. Cochrane Database Syst Rev: CD003792.

20. Reid WD, Geddes EL, O'Brien K, Brooks D, Crowe J (2008) Effects of inspiratory muscle training in cystic fibrosis: a systematic review. Clin Rehabil 22: $1003-1013$

21. Xiao Y, Luo M, Wang J, Luo H (2012) Inspiratory muscle training for the recovery of function after stroke. Cochrane Database Syst Rev 5: CD009360.

22. Gosselink R, De Vos J, van den Heuvel SP, Segers J, Decramer M, et al. (2011) Impact of inspiratory muscle training in patients with COPD: what is the evidence? Eur Respir J 37: 416-425.

23. Lötters F, van Tol B, Kwakkel G, Gosselink R (2002) Effects of controlled inspiratory muscle training in patients with COPD: a meta-analysis. Eur Respir J 20: $570-577$

24. McConnell AK, Romer LM (2004) Dyspnoea in health and obstructive pulmonary disease: the role of respiratory muscle function and training. Sports Med 34: 117-132.

25. Busch V, Magerl W, Kern U, Haas J, Hajak G, et al. (2012) The effect of deep and slow breathing on pain perception, autonomic activity, and mood processing--an experimental study. Pain Med 13: 215-228.

26. Chalaye P, Goffaux P, Lafrenaye S, Marchand S (2009) Respiratory effects on experimental heat pain and cardiac activity. Pain Med 10: 1334-1340.

27. Chambers CT, Taddio A, Uman LS, McMurtry CM, HELPinKIDS Team (2009) Psychological interventions for reducing pain and distress during routine childhood immunizations: a systematic review. Clin Ther 31: S77-S103.

28. de Jong AE, Gamel C (2006) Use of a simple relaxation technique in burn care: literature review. J Adv Nurs 54: 710-721.
29. Downey LV, Zun LS (2009) The effects of deep breathing training on pain management in the emergency department. South Med J 102: 688-692.

30. Field T (2008) Pregnancy and labor alternative therapy research. Altern Ther Health Med 14: 28-34.

31. Yildirim G, Sahin NH (2004) The effect of breathing and skin stimulation techniques on labour pain perception of Turkish women. Pain Res Manag 9 183-187.

32. Chapman RF, Stager JM, Tanner DA, Stray-Gundersen J, Levine BD (2011) Impairment of 3000-m run time at altitude is influenced by arterial oxyhemoglobin saturation. Med Sci Sports Exerc 43: 1649-1656.

33. Saunders PU, Pyne DB, Gore CJ (2009) Endurance training at altitude. High Alt Med Biol 10: 135-148.

34. Johnson MA, Sharpe GR, Brown PI (2007) Inspiratory muscle training improves cycling time-trial performance and anaerobic work capacity but not critical power. Eur J Appl Physiol 101: 761-770.

35. Mourya M, Mahajan AS, Singh NP, Jain AK (2009) Effect of slow- and fastbreathing exercises on autonomic functions in patients with essential hypertension. J Altern Complement Med 15: 711-717.

36. Wang SZ, Li S, Xu XY, Lin GP, Shao L, et al. (2010) Effect of slow abdomina breathing combined with biofeedback on blood pressure and heart rate variability in prehypertension. J Altern Complement Med 16: 1039-1045.

37. May O, Arildsen H, Møller M (1999) Parasympathetic function during deep breathing in the general population: relation to coronary risk factors and normal range. J Intern Med 245: 287-294.

38. Jerath R, Edry JW, Barnes VA, Jerath V (2006) Physiology of long pranayamic breathing: neural respiratory elements may provide a mechanism that explains how slow deep breathing shifts the autonomic nervous system. Med Hypotheses 67: 566-571.

39. Pramanik T, Pudasaini B, Prajapati R (2010) Immediate effect of a slow pace breathing exercise Bhramari pranayama on blood pressure and heart rate. Nepal Med Coll J 12: 154-157.

40. Rosengård-Bärlund $M$, Bernardi L, Holmqvist J, Debarbieri G, Mäntysaari M, et al. (2011) Deep breathing improves blunted baroreflex sensitivity even after 30 years of type 1 diabetes. Diabetologia 54: 1862-1870.

41. Rahman I, Kinnula VL (2012) Strategies to decrease ongoing oxidant burden in chronic obstructive pulmonary disease. Expert Rev Clin Pharmacol 5 : 293-309.

42. Jammes Y, Steinberg JG, Ba A, Delliaux S, Brégeon F (2008) Enhanced exercise-induced plasma cytokine response and oxidative stress in COPD patients depend on blood oxygenation. Clin Physiol Funct Imaging 28: 182 188 